Check for updates

Cite this: Phys. Chem. Chem. Phys., 2017, 19, 13788

Received 3rd March 2017 Accepted 3rd May 2017

DOI: $10.1039 / c 7 c p 01393 k$

rsc.li/pccp

\title{
Non-zeolitic properties of the dipeptide L-leucyl-L-leucine as a result of the specific nanostructure formation $\dagger$
}

\author{
Marat A. Ziganshin, (D)*a Aisylu S. Safiullina, (D) ${ }^{\text {a }}$ Sufia A. Ziganshina, (D) ${ }^{b}$ \\ Alexander V. Gerasimov (D) and Valery V. Gorbatchuk (D)
}

\begin{abstract}
The non-zeolitic behavior of L-leucyl-L-leucine and its self-organization in solid state and from solutions with the formation of different nanostructures are reported. This dipeptide forms porous crystals, but does not exhibit molecular sieve effects typical of classical zeolites and biozeolites. The specific sorption properties of L-leucyl-L-leucine result from a change in its crystal packing from channeltype to layered-type, when binding strong proton acceptors or proton donors of molecular size greater than 18-20 $\mathrm{cm}^{3} \mathrm{~mol}^{-1}$. The high sorption capacity of L-leucyl-L-leucine toward dichloromethane results from the self-organization of the dipeptide, by forming nanofibers or web-like structures. The low thermal stability of clathrates of the dipeptide containing large guest molecules and the selectivity of L-leucyl-L-leucine toward alcohols over nitriles can be used to separate organic mixtures such as methanol/n-butanol and methanol/acetonitrile.
\end{abstract}

\section{Introduction}

Short-chain oligopeptides along with well-studied non-peptide oligomers which are capable of self-organizing in solutions and in solid phase are attractive building blocks for the design of new nanostructured materials with complex, hierarchical architectures. ${ }^{1,2}$ Oligopeptide based materials can have specific properties, such as piezoelectric activity, specific electrochemical behavior, high optical nonlinearity and nanoscale wettability, ${ }^{3}$ as well as magnetic susceptibility ${ }^{4}$ and luminescence. ${ }^{5}$ So, oligopeptide materials are of great interest for a variety of technologies ${ }^{3,5}$ and in medicine. ${ }^{6,7}$

Based on oligopeptides, stable physical hydrogels ${ }^{8}$ and hydrogel nanoparticles, ${ }^{9}$ high-performance catalysts, ${ }^{10}$ biomedical materials with piezoelectric properties, ${ }^{11}$ flexible organic-inorganic hybrid systems for nanotechnology and biomedical science, ${ }^{12}$ biodegradable hybrid materials for electronics ${ }^{13}$ and materials for optoelectronic devices ${ }^{14}$ may be synthesized. Oligopeptides are also successfully used for the fabrication of biosensors ${ }^{15}$ and 2D-ordered films, ${ }^{16}$ and as lithographic masks. ${ }^{17}$

\footnotetext{
${ }^{a}$ A. M. Butlerov Institute of Chemistry, Kazan Federal University, Kremlevskaya ul. 18, Kazan, 420008, Russia.E-mail: Marat.Ziganshin@kpfu.ru

${ }^{b}$ Kazan Zavoisky Physical-Technical Institute of the Kazan Scientific Center of the Russian Academy of Sciences, Sibirskii trakt 10/7, Kazan, 420029, Russia

$\dagger$ Electronic supplementary information (ESI) available: Experimental and calculated powder diffractograms; TG/DSC/MS data of the products of L-leucyl-L-leucine saturation with guest vapors; AFM images of the crystals obtained from a pyridine solution on the HOPG surface; Powder diffraction data. See DOI: 10.1039/c7cp01393k
}

The type of oligopeptide nanomaterial depends on the sequence $^{18,19}$ and number ${ }^{20,21}$ of amino acid residues, types of protecting groups in the oligopeptide molecule, ${ }^{22}$ the type of solvent or solvent ratios from which the oligopeptide is crystallized, ${ }^{18,23,24}$ whether the oligopeptide is prepared at high ${ }^{25}$ or low $^{26}$ temperature, exposure to ultraviolet irradiation, ${ }^{27}$ the type of surface on which the self-organization of the oligopeptide occurs, ${ }^{28,29}$ and the presence of water $^{30}$ or other trace species ${ }^{31}$ within the solvent. These factors complicate the prediction of nanostructures formed under different conditions, but also allow for a huge variety of nanostructures with wide ranging properties.

Some short-chain oligopeptides can form porous crystals ${ }^{32}$ with hydrophobic or hydrophilic layers or channels. ${ }^{33}$ As a result, such crystals exhibit zeolite-like properties, ${ }^{34,35}$ and can selectively bind some gases ${ }^{36,37}$ or separate mixtures of gases. ${ }^{38,39}$

The weak interactions between the monomer units in oligopeptide crystals leads to a complex dependence of the oligopeptides sorption properties on the molecular size of the sorbate (i.e. guest). ${ }^{19}$ This may cause changes in the packing of the oligopeptide, ${ }^{40-42}$ and can even destroy the crystal ${ }^{43}$ during the binding of vapor-phase guests. The sorption capacity of oligopeptide crystals generally decreases with increasing molecular size of the sorbate in homologous series. ${ }^{19}$

Some oligopeptide crystals obtained from solutions exhibit unusual sorption capacities. For example, the dipeptide L-leucyl-Lleucine (Leu-Leu) forms isomorphous 1:1 solvates with ethanol, 1-propanol, 2-propanol, ${ }^{44}$ 2-methyl-1-propanol ${ }^{45}$ and $1:(0.5: 0.5)$ with 1-propanol:2-propanol mixtures. ${ }^{44}$ Transitioning from 
ethanol to propanols constitutes a 1.35 times increase in molecular size, according to molecular refraction $\left(\mathrm{MR}_{\mathrm{D}}\right)$ values. However, the cell parameters of the channel-type crystalline Leu-Leu do not significantly change. Transitioning from ethanol to isobutanol constitutes a 1.7 times increase in molecular size, which does significantly change the crystal parameters of Leu-Leu. In the latter case, layered crystals of Leu-Leu form with isobutanol. ${ }^{45}$ Layered crystals of the same composition of Leu-Leu also form with dimethyl sulfoxide (DMSO), ${ }^{46}$ but the crystal cell parameters differ significantly from those of Leu-Leu with 2-methyl-1-propanol, despite the similar sizes of DMSO and 2-methyl-1-propanol. With water, the dipeptide forms crystals with a composition of $0.87 \mathrm{~mol}$ of $\mathrm{H}_{2} \mathrm{O}$ per mol of Leu-Leu. ${ }^{47}$ In these crystals, solvent molecules form hydrogen bonds with one or two dipeptide molecules. The difficulty in preparing Leu-Leu crystals with organic guests has resulted in the data reported on the interaction of Leu-Leu for only six compounds, three of which are homologues. ${ }^{44-47}$ This information is insufficient for predicting the sorption properties of the dipeptide in "solid Leu-Leu + vapor" systems.

The present work is the first reported comprehensive study of the sorption properties of Leu-Leu toward a wide range of organic compounds, including proton donors, proton acceptors and aprotic compounds. The data presented herein reveal the non-zeolite properties of this dipeptide. Different experimental methods are used to investigate and explain the specific sorption properties of the dipeptide. The sorption of organic vapors or water by a dipeptide layer was studied on a quartz crystal microbalance (QCM-sensor). The thermal stabilities of the products of the interaction of Leu-Leu with vapors were studied using thermogravimetric analysis with simultaneous differential scanning calorimetry, and mass-spectrometry detection of the evolved vapors. The self-organization (we use this term rather than self-assembly because of the non-equilibrium conditions of the systems studied ${ }^{48}$ ) of the dipeptide in solutions, and the effect of vapors on the surface morphologies of thin dipeptide films were observed by atomic force microscopy. Changes in the crystal packing of Leu-Leu were characterized by X-ray powder diffraction.

\section{Experimental}

\section{Materials}

The dipeptide L-leucyl-L-leucine (Leu-Leu) (Bachem) was used without additional purification.

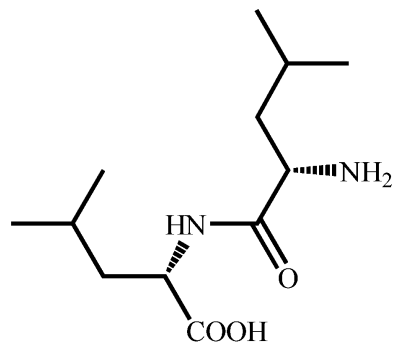

Leu-Leu

Purified organic solvents ${ }^{49}$ had at least $99.5 \%$ purity.

\section{QCM study of guest binding}

A sensor device with $10 \mathrm{MHz}$ QCM crystals in thickness shear mode (TSM) was used. ${ }^{50}$ The dipeptide coatings were prepared on the gold surface of quartz crystals. ${ }^{19}$ These coatings lead to a decrease of $\Delta F \sim 800 \mathrm{~Hz}$ in the crystal frequency after solvent removal. The thickness value $(\sim 40 \mathrm{~nm})$ was estimated by the layer area, mass and density of Leu-Leu $\rho=1.156 \mathrm{~g} \mathrm{~cm}^{-3}$, calculated from X-ray single crystal data. ${ }^{47}$

QCM sensor experiment has been carried out as describe elsewhere. ${ }^{19,43}$ The stoichiometry of clathrates was determined with an error of $10 \%$. The residual water content in these coatings, determined as describe elsewhere, ${ }^{43}$ does not exceed $1.0 \mathrm{w} / \mathrm{w} \%$.

\section{Thermoanalysis by simultaneous TG/DSC/MS}

Simultaneous thermogravimetry (TG) and differential scanning calorimetry (DSC) analysis of dipeptide powder with mass spectrometric (MS) evolved gas analysis was performed using an STA 449 C Jupiter (Netzsch) thermoanalyzer coupled with a QMS 403C Aeolos (Netzsch) quadrupolar mass-spectrometer as described elsewhere. ${ }^{50,51}$

\section{X-ray powder diffraction (XRPD)}

XRPD studies of the dipeptide were performed using a MiniFlex 600 diffractometer (Rigaku) equipped with a D/teX Ultra detector. $^{52}$ In this experiment, $\mathrm{Cu} \mathrm{K} \alpha$ radiation $(40 \mathrm{kV}, 15 \mathrm{~mA})$ was used and data were collected at room temperature in the range of $2 \theta$ from 3 to 50 with a step of 0.02 and exposure time at each point of $0.24 \mathrm{~s}$ without sample rotation.

\section{Atomic force microscopy (AFM).}

AFM images were recorded using a Titanium (NT-MDT, Russia) atomic force microscope. Measurements were performed in air using a tapping mode. ${ }^{19,43}$ The revolution cartridge of cantilevers CNG (NT-MDT, Russia) was used. For AFM experiments, dipeptide films with a diameter of $3 \mathrm{~mm}$ were prepared from different solutions on the surfaces of highly oriented pyrolytic graphite (HOPG) plates $(1 \times 1 \mathrm{~cm})$ using the same technique as for the QCM study. ${ }^{19}$ HOPG was freshly cleaved before use. To study the effects of vapors on the film morphology, first, an AFM image was obtained for the initial dipeptide film dried from methanol solution. Then, the dipeptide layer was saturated with water or organic vapors. Thereafter, the guest was removed from the dipeptide as for the sensor experiment, ${ }^{53}$ and the AFM image of the film was obtained.

\section{Results and discussion}

The QCM sensor responses $(\Delta F)$ of the quartz crystals coated with Leu-Leu were determined for the vapors of 19 organic guests and water at a relative vapor pressure of $P / P_{0}=0.85$ at $298 \mathrm{~K}$. Typical sensor responses for the guest vapors are given in Fig. 1.

The guest/host molar ratio $S$ (Table 1) was calculated using the equation:

$$
S=\left(\Delta F / \Delta F_{\text {dipeptide }}\right) \times\left(M_{\text {dipeptide }} / M_{\text {guest }}\right),
$$




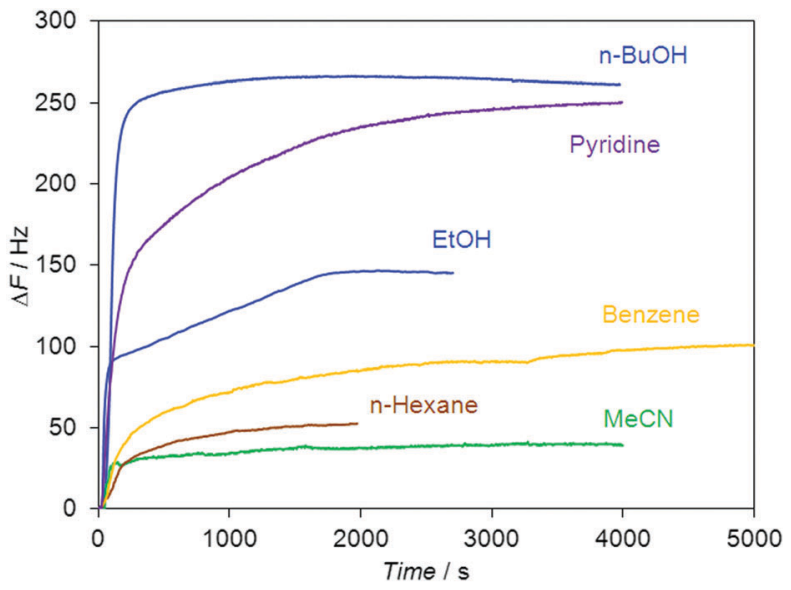

Fig. 1 Responses of the QCM sensor coated with the dipeptide Leu-Leu to organic vapors with relative vapor pressure $P / P_{0}=0.85$ at $T=298 \mathrm{~K}$. Sensor responses $\Delta F$ are normalized to the coating mass with a corresponding frequency decrease of $\Delta F_{\text {dipeptide }}=800 \mathrm{~Hz}$.

Table 1 Guest content in the dipeptide according to QCM sensor data

\begin{tabular}{lll}
\hline Guest & $\mathrm{MR}_{\mathrm{D}}{ }^{a}\left(\mathrm{~cm}^{3} \mathrm{~mol}^{-1}\right)$ & $S\left(\mathrm{~mol}\right.$ guest $\mathrm{mol}^{-1}$ Leu-Leu $)$ \\
\hline $\mathrm{H}_{2} \mathrm{O}$ & 3.7 & $1.09(0.87)^{b}$ \\
$\mathrm{CH}_{3} \mathrm{OH}$ & 8.3 & 1.02 \\
$\mathrm{C}_{2} \mathrm{H}_{5} \mathrm{OH}$ & 12.9 & $0.97(1.0)^{c}$ \\
$n-\mathrm{C}_{3} \mathrm{H}_{7} \mathrm{OH}$ & 17.5 & $1.09(1.0)^{c}$ \\
$\mathrm{i}-\mathrm{C}_{3} \mathrm{H}_{7} \mathrm{OH}$ & 17.6 & $1.08(1.0)^{c}$ \\
$n-\mathrm{C}_{4} \mathrm{H}_{9} \mathrm{OH}$ & 22.1 & 1.10 \\
$\mathrm{CH}_{3} \mathrm{CN}$ & 11.1 & 0.31 \\
$\mathrm{C}_{2} \mathrm{H}_{5} \mathrm{CN}$ & 16.0 & 0.22 \\
$\mathrm{C}_{3} \mathrm{H}_{7} \mathrm{CN}$ & 20.4 & 0.17 \\
$\mathrm{C}_{4} \mathrm{H}_{9} \mathrm{CN}$ & 25.2 & 0.16 \\
$c y c l o-\mathrm{C}_{6} \mathrm{H}_{12}$ & 27.7 & 0.20 \\
$n-\mathrm{C}_{6} \mathrm{H}_{14}$ & 29.9 & 0.19 \\
$n-\mathrm{C}_{7} \mathrm{H}_{16}$ & 34.5 & 0.16 \\
$\mathrm{CH}_{2} \mathrm{Cl}$ & 16.4 & 1.30 \\
$\mathrm{CHCl}_{3}$ & 21.3 & 1.83 \\
$\mathrm{CCl}_{4}$ & 26.4 & 0.37 \\
$\mathrm{C}_{6} \mathrm{H}_{6}$ & 26.3 & 0.41 \\
$\mathrm{C}_{6} \mathrm{H}_{5} \mathrm{CH}_{3}$ & 31.1 & 0.35 \\
$\mathrm{C}_{5} \mathrm{H}_{5} \mathrm{~N}$ & 24.2 & 0.97 \\
$\mathrm{CH}_{3} \mathrm{NO}_{2}$ & 12.5 & 0.28
\end{tabular}

${ }^{a}$ Molar refraction $\mathrm{MR}_{\mathrm{D}}=(M / d) \times\left(n_{\mathrm{D}}{ }^{2}-1\right) /\left(n_{\mathrm{D}}{ }^{2}+2\right)$, where $M$ is the molecular weight of the guest, and $d$ and $n_{\mathrm{D}}$ are the density and refractive index of the liquid guest, respectively. ${ }^{b} \mathrm{X}$-ray data from ref. $47 .{ }^{c} \mathrm{X}$-ray data from ref. 44.

where $\Delta F_{\text {dipeptide }}$ is the frequency change corresponding to the dipeptide mass, and $M_{\text {dipeptide }}$ and $M_{\text {guest }}$ are the molar weights of the dipeptide and guest, respectively.

The observed values of guest content $S$ in Leu-Leu saturated with water, ethanol and propanols are in good agreement with single crystal XRD data for the corresponding inclusion compounds. ${ }^{44,47}$ Also, the content of $n$-butanol, calculated from QCM data, corresponds to the content of isobutanol in the crystal of the dipeptide. ${ }^{45}$

$\mathrm{MR}_{\mathrm{D}}$ values were used as size parameters for guest molecules, ${ }^{19,51,54}$ to analyze the effect of guest size on the sorption capacity of Leu-Leu. The correlation between the stoichiometry of the complexes and the $\mathrm{MR}_{\mathrm{D}}$ values of the guest molecules has been plotted in Fig. 2a.
From this correlation, the studied guests can be divided into two groups. Guests from the first group form clathrates in which the stoichiometry $S$ is $\geq 1 \mathrm{~mol}$ of guest per mol of dipeptide. Guests from the second group form clathrates in which the stoichiometry $S$ is $<0.4 \mathrm{~mol}$ of guest per mol of dipeptide. Proton donors (water, alcohols, and chloroform), strong proton acceptors (pyridine), and dichloromethane constituted the first group. The second group consisted of weak proton acceptors (nitriles, and nitromethane), tetrachloromethane, arenes, and alkanes. Similar selectivities toward alcohols and nitriles were previously reported for the tripeptide L-leucyl-L-leucyl-L-leucine (Leu-Leu-Leu). ${ }^{43}$ The sorption capacities of Leu-Leu-Leu toward water and proton acceptors were similar. The main difference in the sorption properties of the tripeptide and dipeptide is the decrease in the stoichiometry $S$ over the homologous series of alcohols in the case of Leu-Leu-Leu, ${ }^{43}$ whereas this value does not change for Leu-Leu.

We have proposed to use the product of sorption capacity (stoichiometry) of the dipeptide $(S)$ and molar refraction of the guest $\left(\mathrm{MR}_{\mathrm{D}}\right)$ as a parameter for comparing the sorption properties of the dipeptide with other sorbates, including zeolite-like adsorbents. This $S \times \mathrm{MR}_{\mathrm{D}}$ value represents the real space volume in the dipeptide phase required to accommodate the guest. We reported a correlation between $S \times \mathrm{MR}_{\mathrm{D}}$ and the effect of guest vapors on the morphology of the tripeptide film. ${ }^{43}$ The dependence of $S \times \mathrm{MR}_{\mathrm{D}}$ on the $\mathrm{MR}_{\mathrm{D}}$ values for water and the homologous series of alcohols is demonstrated in Fig. 2b. A linear increase of the $S \times \mathrm{MR}_{\mathrm{D}}$ value by $175 \%$ was observed in the range from $\mathrm{MeOH}$ to $n-\mathrm{BuOH}$.

The observed dependence shows an increase in the accessible volume for the guest in the dipeptide with increasing guest molecular size. This behavior is similar to that of clathrateforming receptors such as calixarenes ${ }^{55}$ but not to that of zeolites. For example, for zeolite A the calculated value of $S \times \mathrm{MR}_{\mathrm{D}}$ decreases upon transitioning from water to $n-\mathrm{PrOH}$ and from $\mathrm{MeOH}$ to $n$-PrOH by 12 and $5 \%$, respectively. ${ }^{56}$ Similar decreases in the sorption capacity of 78 and $8 \%$ were observed for zeolites $\mathrm{NaA}$ and $\mathrm{CaA}$, respectively, upon transitioning from the sorbate $\mathrm{MeOH}$ to $n$-PrOH. ${ }^{57}$ A largely constant value of $S \times \mathrm{MR}_{\mathrm{D}}$ has also been observed for the sorption of benzene and toluene by faujasite zeolites. ${ }^{56}$ For human serum albumin, ${ }^{58}$ the dipeptides valyl-alanine and alanyl-valine, ${ }^{19}$ and first generation organophosphorus dendrimers, ${ }^{59}$ the value of $S \times \mathrm{MR}_{\mathrm{D}}$ decreases over the homologous series of alcohols.

The observed specific sorption behavior of Leu-Leu may be due to two reasons. Firstly, hydrogen bonds are likely to form between Leu-Leu and guests such as methanol, n-butanol, chloroform, and pyridine as was similarly demonstrated for water, ${ }^{47}$ ethanol, and propanols. ${ }^{44}$ Secondly, a change in the packing of Leu-Leu from channel-type to layered crystals may occur upon sorption of molecules with $\mathrm{MR}_{\mathrm{D}}$ values larger than $18-20 \mathrm{~cm}^{3} \mathrm{~mol}^{-1}$ (i.e. larger than propanols), as is inferred from the crystal packing of Leu-Leu with 2-methyl-1-propanol ${ }^{45}$ and DMSO. ${ }^{46}$ As a result, an additional volume appears in the dipeptide phase, in the presence of sorbates capable to forming strong hydrogen bonds. This selectivity of the dipeptide toward 

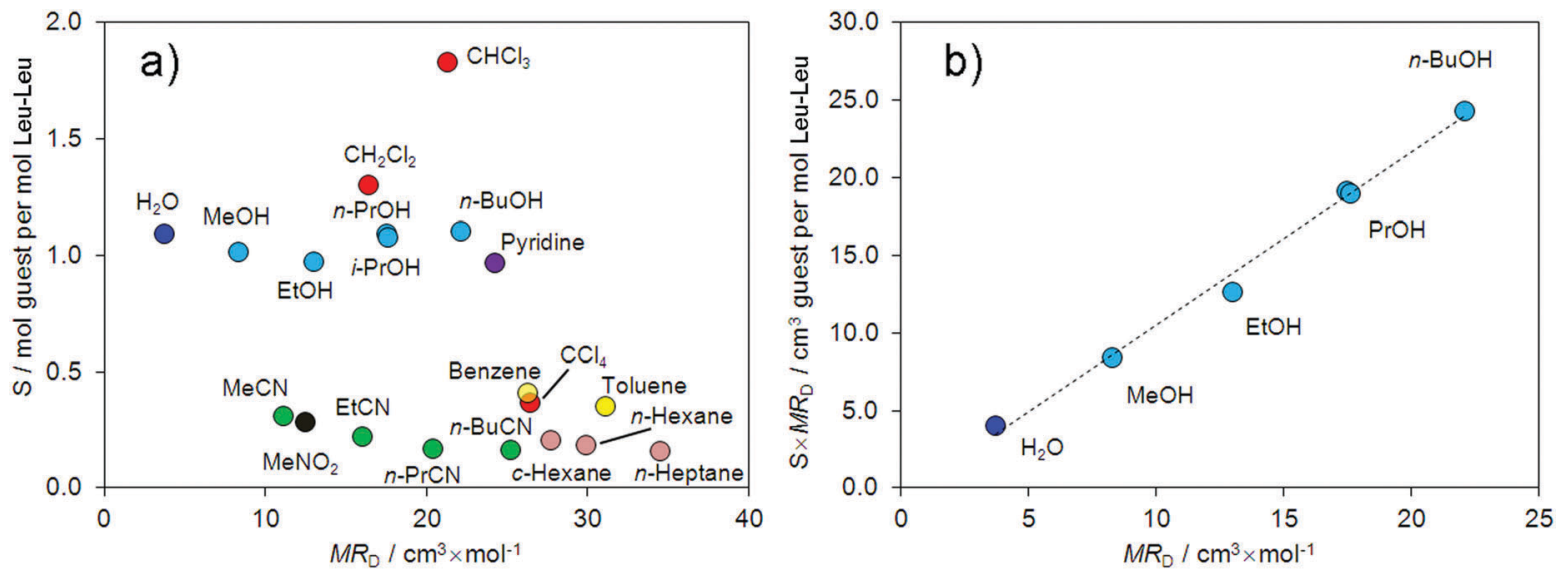

Fig. 2 Correlation of (a) the guest content $S$ in Leu-Leu with guest molar refraction $M R_{D}$ and (b) $S \times M R_{D}$ parameter with molar refraction of the guest.

alcohols over nitriles may be used to separate mixtures of these compounds, even when their molecular sizes are similar. This assumption was tested in the current study using thermal analysis. We also propose an explanation for the high sorption capacity of Leu-Leu toward dichloromethane, which cannot form hydrogen bonds.

Before studying the thermal decomposition of clathrates of the dipeptide, we investigated the thermal properties of the initial Leu-Leu powder. The data obtained from TG/DSC/MS analysis are shown in Fig. 3. Upon heating, the Leu-Leu powder exhibited weight losses of 4.74 and $7.14 \%$ at 124 and $177{ }^{\circ} \mathrm{C}$, respectively. The differential thermogravimetric (DTG) peaks corresponding to these processes were observed at 130 and $180{ }^{\circ} \mathrm{C}$, respectively. Mass spectrometry indicated that these changes in sample weight had $\mathrm{m} / \mathrm{z}$ ratios of 18 , and so were associated with the loss of water (Fig. 3). The first step of weight loss was assumed to result from the evaporation of bound water, and the second to the chemical reaction, involving the formation of amide bonds, as was reported for diphenylalanine. ${ }^{52}$

X-ray powder diffraction was then used to test this assumption. XRPD patterns of the initial Leu-Leu powder (Fig. 4a) and samples after heating to 130 (Fig. 4b) and $180^{\circ} \mathrm{C}$ (Fig. 4d) were obtained. XRPD patterns of the heated samples after their saturation with

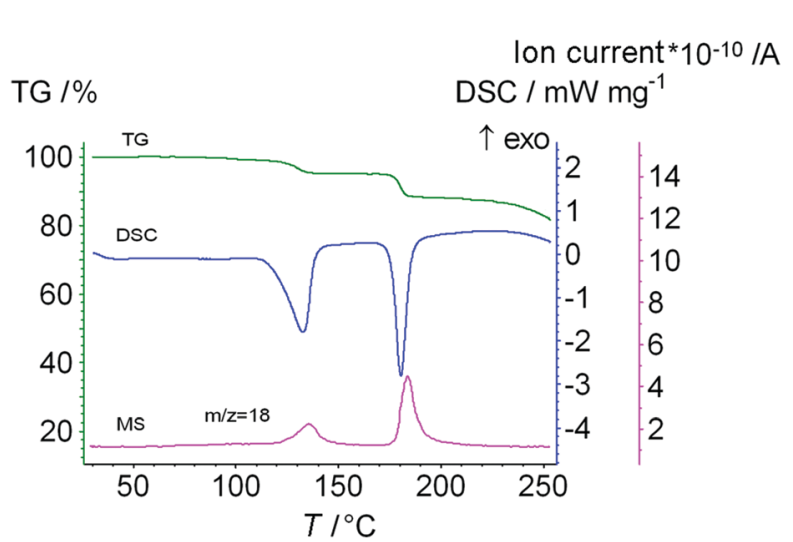

Fig. 3 The data from TG/DSC/MS analysis of the initial Leu-Leu sample. The heating rate is $10 \mathrm{~K} \mathrm{~min}$.

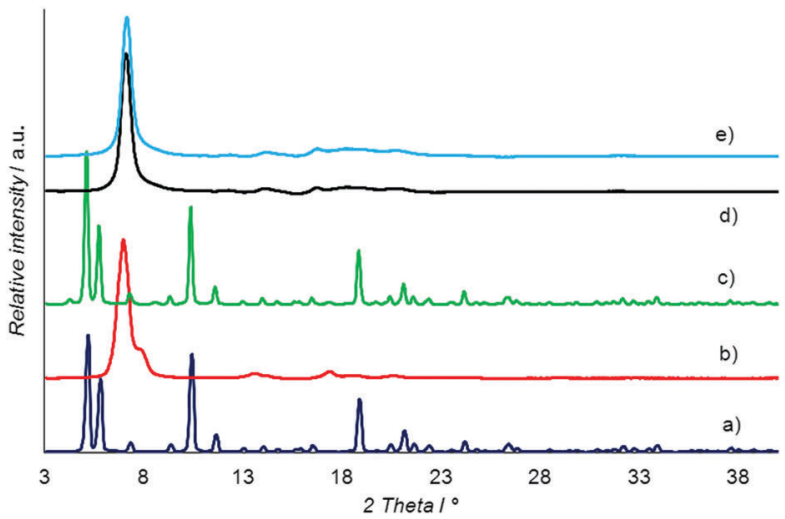

Fig. 4 X-ray powder diffractograms of Leu-Leu: (a) initial powder, (b) sample after heating up to $130{ }^{\circ} \mathrm{C}$, (c) sample (b) after contact with saturated vapors of water for 3 days, (d) sample after heating up to $180^{\circ} \mathrm{C}$, and (e) sample (d) after contact with liquid water for 5 days.

water were also obtained. For this purpose, the samples after heating to 130 and $180^{\circ} \mathrm{C}$ were kept in contact with saturated water vapor for 3 days (Fig. $4 \mathrm{c}$ ) and liquid water for 5 days at $25{ }^{\circ} \mathrm{C}$ (Fig. 4e).

The XRPD patterns of the initial Leu-Leu powder (Fig. 4a) and powder saturated with water after heating to $130{ }^{\circ} \mathrm{C}$ (Fig. 4c) had similar profiles, and were comparable to the XRPD pattern simulated from single crystal X-ray data for Leu-Leu monohydrate, ${ }^{47}$ ESI. $\dagger$ The XRD pattern of the sample heated to $130{ }^{\circ} \mathrm{C}$ (Fig. 4b) contained a strong peak at $2 \theta$ of $6.9^{\circ}$ with a shoulder at $7.5^{\circ}$, and weaker peaks at $13.4,17,18.5$, and $20.4^{\circ}$. A similar pattern with an intense peak at $7^{\circ}$ and broad weaker peaks at $13.8,16.5,18$, and $20^{\circ}$ was obtained for Leu-Leu after heating to $180{ }^{\circ} \mathrm{C}$ (Fig. 4d). The XRPD pattern of this powder sample showed no appreciable change after contact with liquid water for 5 days (Fig. 4e).

The heated samples were also investigated using thermal analysis after saturating with water (ESI $\dagger$ ). Recovery of the initial water content was observed for the sample heated to $130{ }^{\circ} \mathrm{C}$, but not for the sample heated to $180{ }^{\circ} \mathrm{C}$.

These experiments show that bound water was lost during the first stage of the TG curve (Fig. 3). Therefore, the mass of 
dry dipeptide $m\left(\right.$ Leu-Leu $\left.\mathrm{dry}_{\mathrm{f}}\right)$ was calculated as the difference between the mass of the initial sample $m\left(\mathrm{Leu}-\mathrm{Leu}_{\mathrm{ini}}\right)$ and the mass loss during the first stage $\Delta m_{1}$, according to the equation:

$$
m\left(\text { Leu-Leu } \mathrm{dry}_{\mathrm{dry}}\right)=m\left(\text { Leu-Leu } \mathrm{u}_{\mathrm{ini}}\right)-\Delta m_{1} .
$$

The water content in the dipeptide $S_{1}$ (mol of water per mol of dry dipeptide) was calculated according to the equation:

$$
S_{1}=\Delta m_{1} \times M_{\text {Leu-Leu }} /\left(M_{\mathrm{H}_{2} \mathrm{O}} \times m(\text { Leu-Leu } \mathrm{dry})\right)
$$

where $M_{\text {Leu-Leu }}$ and $M_{\mathrm{H}_{2} \mathrm{O}}$ are the molecular weight of the dipeptide and water, respectively.

The amount of water $S_{2}$ (mol of water per mol of dry dipeptide) which was lost during the second step of the TG-curve was calculated according to the equation:

$$
S_{2}=\Delta m_{2} \times M_{\text {Leu-Leu }} /\left(M_{\mathrm{H}_{2} \mathrm{O}} \times m\left(\text { Leu-Leu } \mathrm{dry}_{\mathrm{f}}\right)\right)
$$

The mass losses during the first $\Delta m_{1}$ (desorption) and second $\Delta m_{2}$ (chemical reaction) steps were calculated to be 4.74 and $7.14 \%$, respectively, which corresponded to 0.7 and $1.0 \mathrm{~mol}$ of water per $1 \mathrm{~mol}$ of dipeptide, respectively.

Further, the decomposition of products of the saturation of the dipeptide with water or organic vapors was studied using TG/DSC/MS analysis (Fig. 5 and ESI $\dagger$ ).

For some clathrates of Leu-Leu with organic compounds, elimination of the organic compound in the first stage has been shown to be associated with the release of water (Fig. 5). Therefore, a correction for the amount of water was made when calculating the content of the organic guest. For this, the MS-calibration was performed in the isothermal mode at $130{ }^{\circ} \mathrm{C}$. ${ }^{60}$ The combined weight of the released water and organic guest was estimated from the ratio of the areas of the $\mathrm{m} / \mathrm{z}=18$ mass spectrometry signals of the initial Leu-Leu sample (containing only water) and the product saturated with the organic sorbate (containing water and the organic sorbate). The content of the organic compound was calculated according to the equation:

$$
S=\left(\Delta m_{1}-\Delta m_{\mathrm{H}_{2} \mathrm{O}}\right) \times M_{\text {Leu-Leu }} /\left(M_{\text {guest }} \times m\left(\text { Leu-Leu }{ }_{\mathrm{dry}}\right)\right)
$$

where $\Delta m_{\mathrm{H}_{2} \mathrm{O}}$ is the mass of water, released with the organic compound in the first step of the TG-curve, $M_{\text {guest }}$ is the molecular weight of the guest.

The thermoanalysis results are given in Table 2 including the mass loss $\Delta m$, clathrate composition $S_{\mathrm{TG}}$, temperature of guest elimination $T_{\text {onset }}$ and temperatures of DTG-peaks $T_{\max }$.

The thermal analysis data indicated that Leu-Leu does not form stable clathrates at room temperature with acetonitrile, benzene, tetrachloromethane and dichloromethane. Only water was detected in the evolved vapor during the decomposition of the products of Leu-Leu saturated with these organic compounds, Table 2. The mass loss corresponded to the content of water in the initial Leu-Leu sample. The temperatures of guest elimination $T_{\text {onset }}$ and the DTG-peaks $T_{\max }$ for these saturated products were higher than the corresponding values for the initial Leu-Leu sample, and for Leu-Leu saturated with water vapor. Leu-Leu saturated with chloroform vapor formed a stable clathrate containing $0.1 \mathrm{~mol}$ of chloroform and $0.2 \mathrm{~mol}$ of water per mol of Leu-Leu. Anhydrous

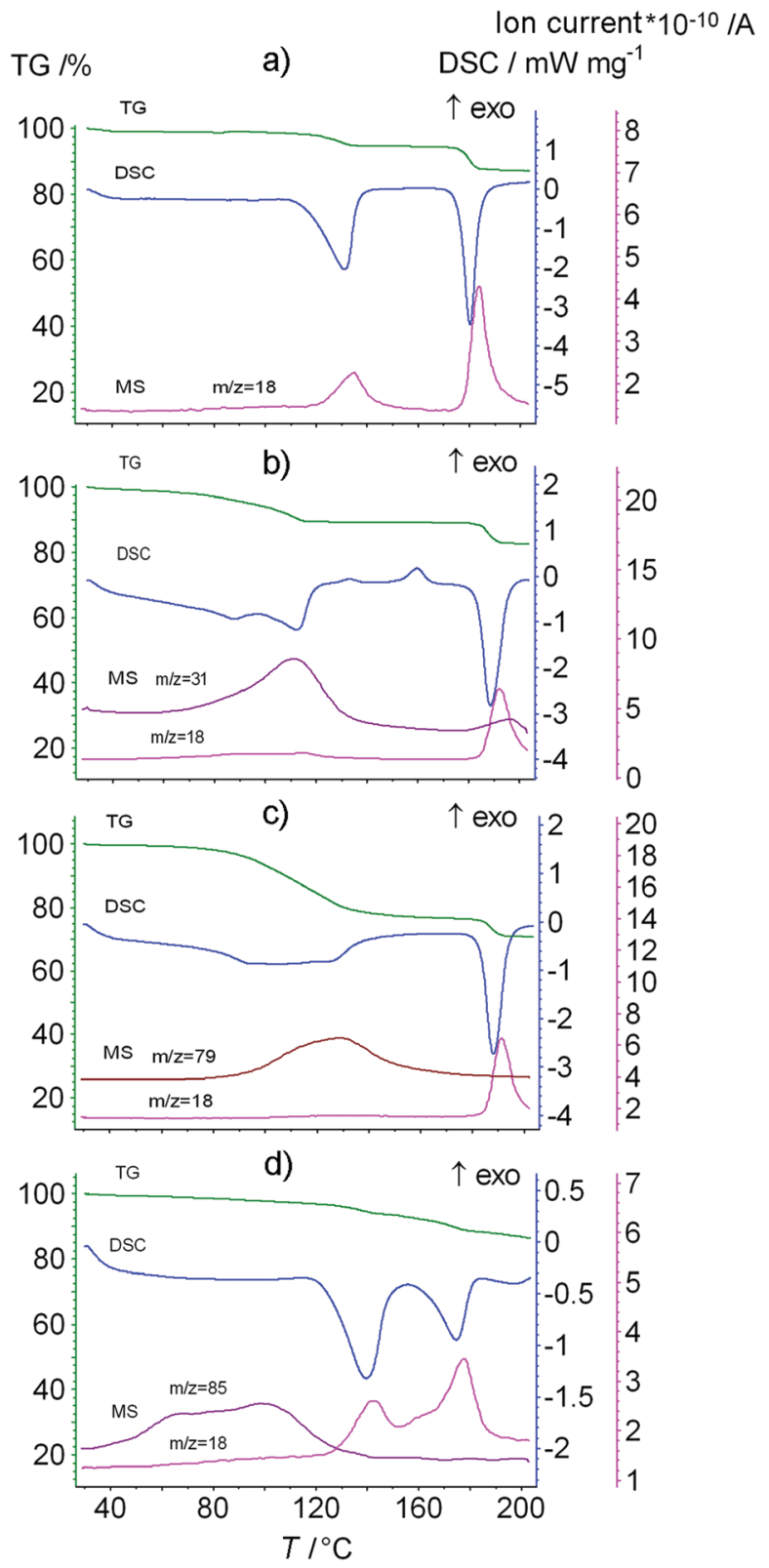

Fig. 5 The data from TG/DSC/MS analysis of the Leu-Leu sample saturated with vapors of (a) water, (b) methanol, (c) pyridine and (d) chloroform. The heating rate is $10 \mathrm{~K} \mathrm{~min}^{-1}$.

clathrates were obtained after saturating Leu-Leu powder with vapors of methanol, $n$-propanol, $n$-butanol and pyridine. Leu-Leu saturated with vapors of ethanol, isopropanol and chloroform contained small water contents, which did not exceed the error of calculation. The content of alcohols and pyridine in the clathrates of Leu-Leu corresponded to the stoichiometry calculated from the QCM sensor data and X-ray diffraction data, Tables 1 and 2.

The $\Delta T=T_{\max }-T_{\mathrm{b}}$ value can be used as a measure of the thermal stability of the clathrates, where $T_{\mathrm{b}}$ is the boiling point of the guest. ${ }^{51}$ For the homologous series of alcohols, there was a decrease in thermal stability of the clathrate with increasing guest boiling temperature. This may indicate a weakening of the interaction between the dipeptide and guest with increasing 
Table 2 The data from simultaneous TG/DSC/MS analysis of clathrates of Leu-Leu with water and organic guests

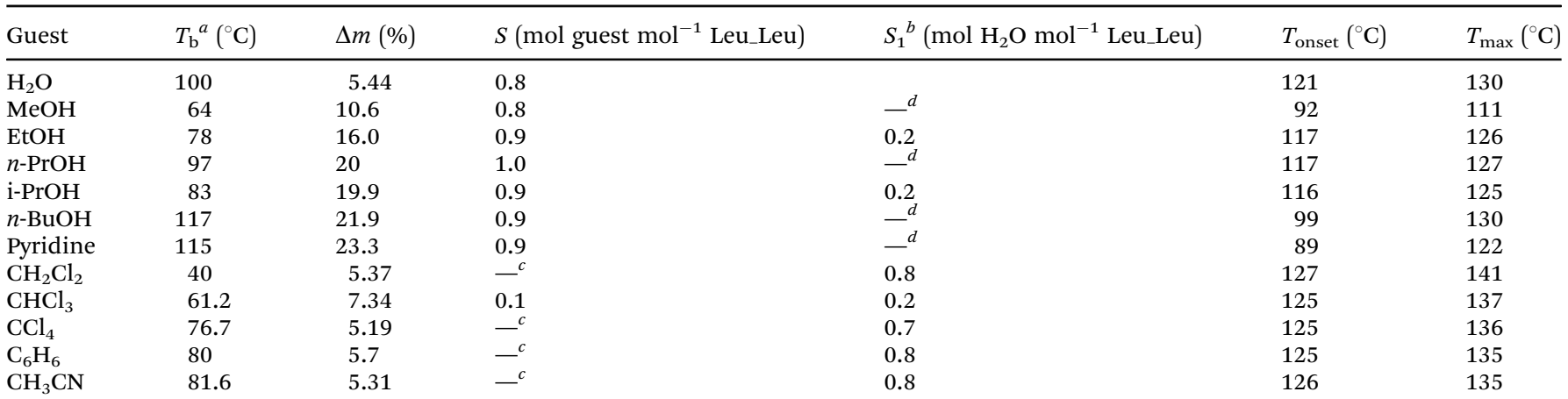

${ }^{a}$ Boiling temperature of liquid sorbates. ${ }^{b}$ Water content in the clathrate estimated from the value of $\Delta m_{\mathrm{H}_{2} \mathrm{O}}$ with an error of $0.2 \mathrm{~mol}$ water per mol of Leu-Leu. ${ }^{c}$ There is only water in the evolved vapors. ${ }^{d}$ The signal of $m / z=18$ is zero.

guest size, because of steric restrictions hindering the optimal packing of larger guest molecules in the dipeptide phase.

The selectivity of the dipeptide toward alcohols over nitriles, and the low stabilities of clathrates containing large guests can be used for practical application. In this study, we demonstrated the separation of methanol/acetonitrile and methanol/ $n$-butanol mixtures by Leu-Leu. Two samples were prepared by saturating Leu-Leu powders with vapors of $1: 1 \mathrm{v} / \mathrm{v} \%$ methanol/ acetonitrile and methanol $/ n$-butanol mixtures for 3 days. Thermal analysis data of the saturated products are shown in Fig. 6, and only methanol vapor was detected in the evolved gases.

The low content of chloroform in the clathrate of Leu-Leu may have resulted from several reasons. Chloroform has a low boiling point, and forms weak hydrogen bonds with acceptors. Methanol has a closer boiling point to chloroform, Table 2, but forms stronger hydrogen bonds with proton acceptors (e.g. acetone), compared with chloroform. ${ }^{61}$ For clathrates of Leu-Leu with pyridine and $n$-butanol, the differences between the temperatures of clathrate decomposition and guest boiling points are 26 and $18{ }^{\circ} \mathrm{C}$, respectively. A similar difference $\left(20-30{ }^{\circ} \mathrm{C}\right)$ could be expected for the clathrate with chloroform, so its decomposition should begin at temperatures near $31-41{ }^{\circ} \mathrm{C}$, Table 2 . This accounted for the loss of most of the chloroform from the clathrate during 15-20 min in argon flow prior to thermal analysis. The formation of the clathrate of Leu-Leu with chloroform was confirmed by the decrease of the dipeptide water content to $0.2 \mathrm{~mol}$ of $\mathrm{H}_{2} \mathrm{O}$ per mol of Leu-Leu, Table 2. For nonbonded guests, the water content of the saturated product is the same as that of the initial clathrate. Thus, the decrease in water content was likely caused by the exchange of chloroform. The high sorption capacity of Leu-Leu toward chloroform (Fig. 2 and Table 1) may be explained by the formation of layered crystals, as in the case of clathrates with pyridine and $n$-butanol because of the similar sizes of these guest molecules.

However, this argument does not account for the high sorption capacity of Leu-Leu toward dichloromethane. Thus, we investigated the self-organization of Leu-Leu from methanol, chloroform, pyridine, and dichloromethane solutions using atomic force microscopy. The effect of ethanol, chloroform and dichloromethane vapors on the morphology of dipeptide films was also studied.

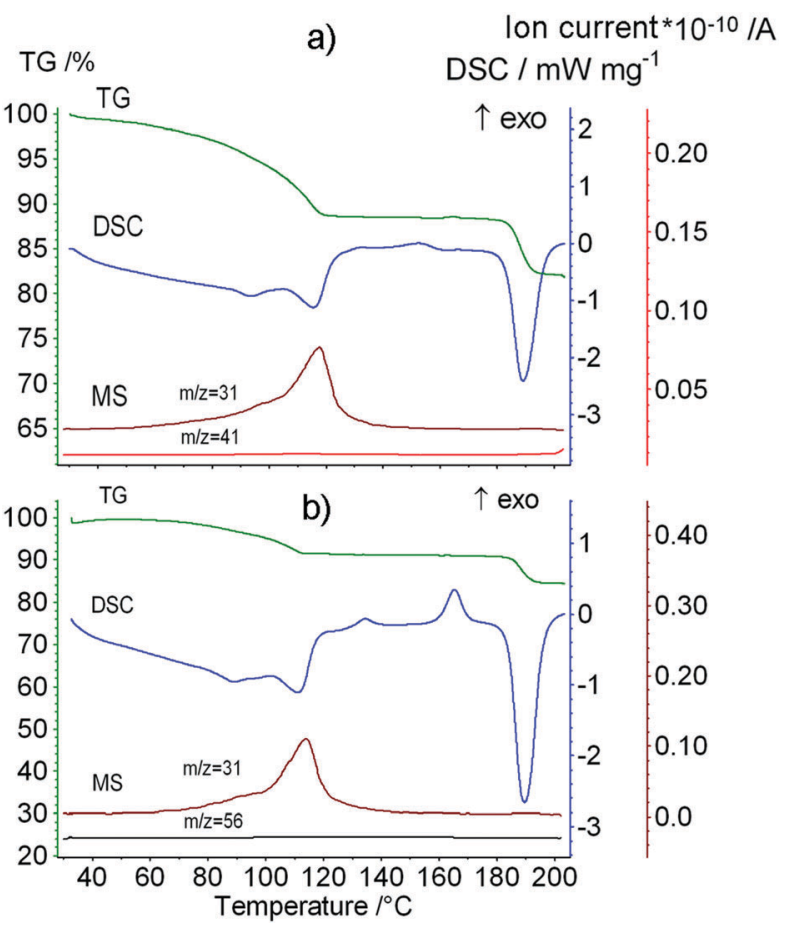

Fig. 6 The data from TG/DSC/MS analysis of the product of Leu-Leu powder saturation with vapors of $1: 1 \mathrm{v} / \mathrm{v} \%$ (a) $\mathrm{MeOH} / \mathrm{MeCN}$ and (b) $\mathrm{MeOH} /$ $n$ - $\mathrm{BuOH}$ mixtures for 3 days. Ion thermograms of methanol $(\mathrm{m} / \mathrm{z}=31)$, acetonitrile $(m / z=41)$ and $n$-butanol $(m / z=56)$. The heating rate is $10 \mathrm{~K} \mathrm{~min}^{-1}$.

Evaporation of methanol from the dipeptide solution led to the formation of a relatively smooth Leu-Leu film, which contained shapeless objects of varying sizes on the surface of highly oriented pyrolytic graphite. The average height spread on a $30 \times 30 \mu \mathrm{m}$ scan was $30 \mathrm{~nm}$ and the mean square roughness of the surface $R_{\mathrm{q}}$ was $5.3 \mathrm{~nm}$ (Fig. 7a). Apparently, the same amorphous film forms on the surface of the QCM sensor.

The saturation of the dipeptide film with ethanol vapor yielded relatively small crystals on its surface (ESI $\dagger$ ) with height, length and width approximately $20-140 \mathrm{~nm}, 0.2-0.85 \mu \mathrm{m}$ and $0.2-0.77 \mu \mathrm{m}$, respectively. 

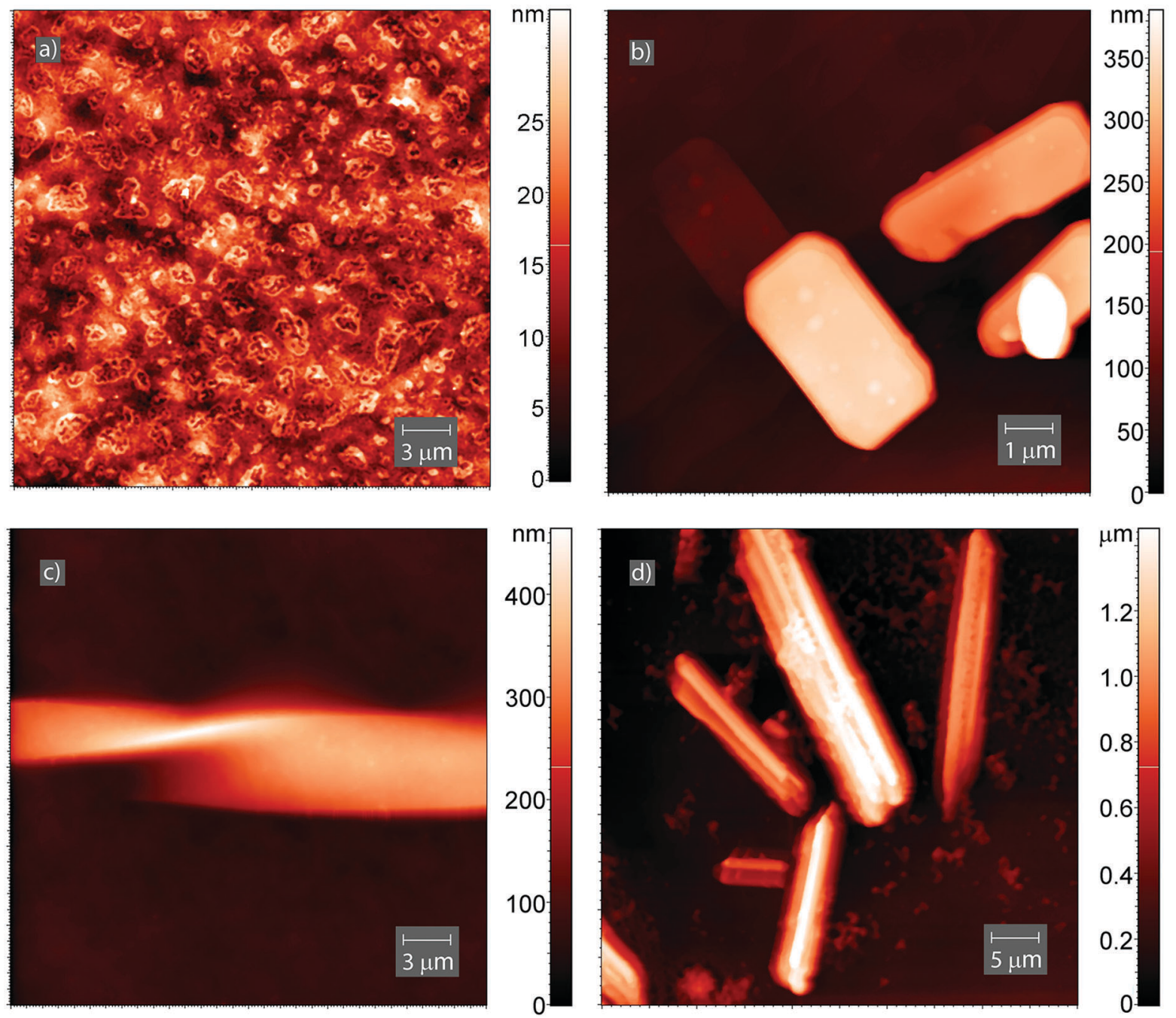

Fig. 7 AFM images of the surface of the Leu-Leu film deposited on HOPG from (a) methanol solution, (b) pyridine solution, (c) methanol solution and saturated with chloroform vapors for 2 days, and (d) chloroform solution.

Evaporation of pyridine solution leads to the formation of flattened octagonal crystals like cut emeralds (Fig. 7b and ESI $\dagger$ ). The height, length and width of a single crystal were approximately $270 \mathrm{~nm}, 4.6 \mu \mathrm{m}$ and $2.7 \mu \mathrm{m}$, respectively. The side face of the crystal contained steps with heights of 20-60 nm (ESI $\dagger$ ).

Exposing the initial Leu-Leu film to saturated chloroform vapor for 2 days yielded elongated crystals on its surface, including a spiral-shaped crystal (Fig. 7c). This crystal has a length more than $50 \mu \mathrm{m}$, width of approximately $9 \mu \mathrm{m}$, and thickness in the twisted region of approximately $190 \mathrm{~nm}$. When chloroform was used as the solvent, the dipeptide crystallized from solution formed elongated crystals with heights of $90 \mathrm{~nm}$ to $1.5 \mu \mathrm{m}$ (Fig. $7 \mathrm{~d}$ and ESI†). The lengths of the crystals are in the range from $300 \mathrm{~nm}$ to $30 \mu \mathrm{m}$. The formation of such large crystals was observed only for the systems with chloroform. One can assume that the crystals formed have a specific packing with a large free internal volume which can accommodate a significant amount of this guest.

Different results were obtained for the initial Leu-Leu film exposed to dichloromethane (Fig. 8). After saturating the
Leu-Leu film with dichloromethane vapor for one day, linear and curved nanofibers with heights of 4-25 $\mathrm{nm}$, lengths of 8-9 $\mu \mathrm{m}$ and base widths of $80-150 \mathrm{~nm}$ were observed on the surface (Fig. 8a and c). The fibers thickened where they intersected with each other (Fig. 8c). Also, the SEM images were obtained for the Leu-Leu film saturated with dichloromethane vapor for $200 \mathrm{~min}$ (ESI†). The lengths of 8-9 $\mu \mathrm{m}$ and widths of 80-150 $\mathrm{nm}$ are in excellent agreement with observations by AFM. Evaporation of dichloromethane from the dipeptide solution yielded a web-like structure, similar to that of dried gels $^{17,62}$ (Fig. 8b and d). The threads had a necklace-like structure, and were composed of small spherical particles with diameters of 40-80 $\mathrm{nm}$. The distances between nodes of the web are in the range from 200 to $800 \mathrm{~nm}$. The web-like structure on HOPG also was observed using SEM (ESI $\dagger$ ). The formation of such nanostructures during the interaction of the dipeptide film with dichloromethane vapor may have caused the high sorption capacity of Leu-Leu, because the gel structure can hold a large amount of solvents (sorbents). ${ }^{63}$ The gelation of Leu-Leu in dichloromethane vapor or solution may have been due to the 

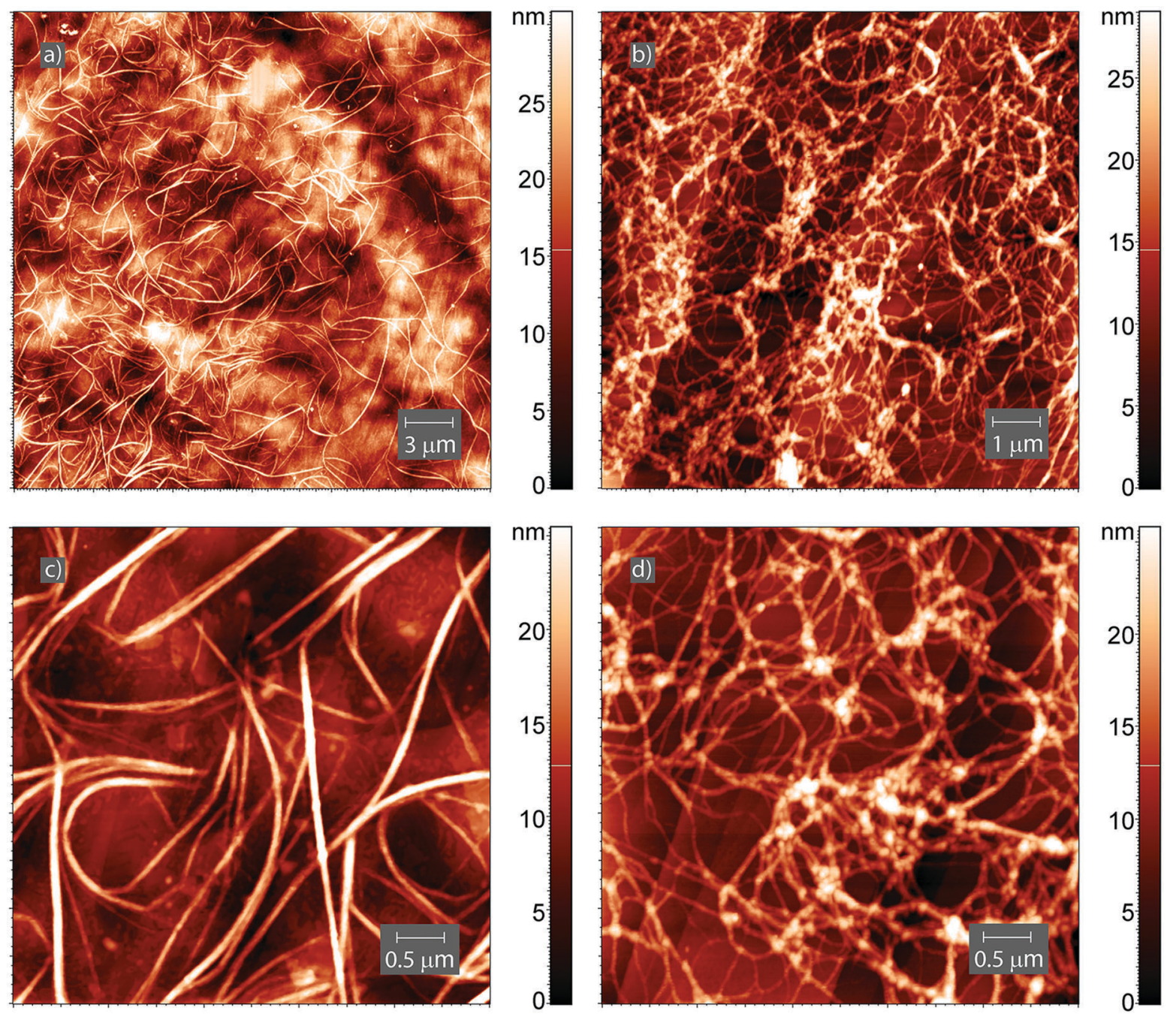

Fig. 8 AFM images of the surface of (a and c) the Leu-Leu film deposited on HOPG from methanol solution after saturation with dichloromethane vapors for 1 day and ( $b$ and $d$ ) the Leu-Leu film deposited on HOPG from dichloromethane solution.

presence of water in the dipeptide. This is similar to the gel formation of diphenylalanine in ethanol $/ \mathrm{CH}_{2} \mathrm{Cl}_{2}$ mixtures containing trace water. ${ }^{31}$

\section{Conclusions}

We have demonstrated the unusual non-zeolitic properties of L-leucyl-L-leucine, which exhibited an increase in the sorption volume of the dipeptide phase with increasing sorbate molecular size. This resulted from a change in the packing of the dipeptide crystals, induced by binding organic molecules larger than $18-20 \mathrm{~cm}^{3} \mathrm{~mol}^{-1}$ that were capable of hydrogen bonding with the dipeptide. A decrease in the thermal stability of the clathrates of L-leucyl-L-leucine with increasing guest size was observed. The dipeptide exhibited selectivity toward alcohols over nitriles. L-Leucyl-L-leucine could bind aliphatic alcohols in 3-5 times higher molar ratios than nitriles, despite their similar molecular sizes. This was exploited for separating methanol $/ n$-butanol and methanol/acetonitrile mixtures.
The solvent strongly affected the crystallization of L-leucyl-Lleucine. Evaporation from methanol solution yielded an amorphous dipeptide film. Evaporation from chloroform and pyridine yielded elongated and flattened octagonal crystals, respectively. Evaporation from dichloromethane yielded a gel-like structure. Exposing thin dipeptide films to saturated chloroform and dichloromethane vapors yielded spiral crystals and separated nanofibers, respectively.

So, using solvents or vapors with different physicochemical properties may allow us to control the type and shape of nanostructures based on L-leucyl-L-leucine by the same technique as used for the amphiphilic derivatives of the tripeptide. ${ }^{64}$ Such an opportunity is of great interest for the design of nanoarchitectures, including anisotropic nanostructures. ${ }^{65}$

We believe that the obtained results may be useful for the practical application of short-chain oligopeptides and for the design of new nanostructured materials.

\section{Competing interest}

The authors declare no competing financial interest. 


\section{Acknowledgements}

This study was supported by grant no. 14.Y26.31.0019 from the Ministry of Education and Science of Russian Federation. The authors thank Dr Lyadov Nikolay, Zavoisky Physical-Technical Institute, Kazan, Russia, for SEM experiments.

\section{Notes and references}

1 S. Kim, J. Kim, H. J. S. Lee and C. B. Park, Small, 2015, 11, 3623-3640.

2 S. Yagai, Bull. Chem. Soc. Jpn., 2015, 88, 28-58.

3 G. Rosenman, P. Beker, I. Koren, M. Yevnin, B. Bank-Srour, E. Mishina and S. Semin, J. Pept. Sci., 2011, 17, 75-87.

4 R. J. A. Hill, V. L. Sedman, S. Allen, P. M. Williams, M. Paoli, L. Adler-Abramovich, E. Gazit, L. Eaves and S. J. B. Tendler, Adv. Mater., 2007, 19, 4474-4479.

5 S. Semin, A. van Etteger, L. Cattaneo, N. Amdursky, L. Kulyuk, S. Lavrov, A. Sigov, E. Mishina, G. Rosenman and T. Rasing, Small, 2015, 11, 1156-1160.

6 Y. Kuang, Y. Gao and B. Xu, Chem. Commun., 2011, 47, 12625-12627.

7 S. Marchesan, A. V. Vargiu and K. E. Styan, Molecules, 2015, 20, 19775-19788.

8 G. Fichman and E. Gazit, Acta Biomater., 2014, 10, 1671-1682. 9 R. Ischakov, L. Adler-Abramovich, L. Buzhansky, T. Shekhter and E. Gazit, Bioorg. Med. Chem., 2013, 21, 3517-3522.

10 K. S. Lee and J. R. Parquette, Chem. Commun., 2015, 51, 15653-15656.

11 K. Ryan, J. G. Beirne, G. Redmond, J. I. Kilpatrick, J. Guyonnet, N.-V. Buchete, A. L. Kholkin and B. J. Rodriguez, ACS Appl. Mater. Interfaces, 2015, 7, 12702-12707.

12 X. Yan, P. Zhu, J. Fei and J. Li, Adv. Mater., 2010, 22, 1283-1287.

13 S. Khanra, T. Cipriano, T. Lam, T. A. White, E. E. Fileti, W. A. Alves and S. Guha, Adv. Mater. Interfaces, 2015, 2, 1500265.

14 Y. Li, L. Yan, K. Liu, J. Wang, A. Wang, S. Bai and X. Yan, Small, 2016, 12, 2575-2579.

15 S. Kogikoski Jr, C. P. Sousa, M. S. Liberato, T. Andrade-Filho, T. Prieto, F. F. Ferreira, A. R. Rocha, S. Guhad and W. A. Alves, Phys. Chem. Chem. Phys., 2016, 18, 3223-3233.

16 N. Hendler, N. Sidelman, M. Reches, E. Gazit, Y. Rosenberg and S. Richter, Adv. Mater., 2007, 19, 1485-1488.

17 T. H. Han, T. Ok, J. Kim, D. O. Shin, H. Ihee, H.-S. Lee and S. O. Kim, Small, 2010, 6, 945-951.

18 H. Erdogan, E. Babur, M. Yilmaz, E. Candas, M. Gordese, Y. Dede, E. E. Oren, G. B. Demire, M. K. Ozturk, M. S. Yavuz and G. Demire, Langmuir, 2015, 31, 7337-7345.

19 M. A. Ziganshin, N. S. Gubina, A. V. Gerasimov, V. V. Gorbatchuk, S. A. Ziganshina, A. P. Chuklanov and A. A. Bukharaev, Phys. Chem. Chem. Phys., 2015, 17, 20168-20177.

20 P. Tamamis, L. Adler-Abramovich, M. Reches, K. Marshall, P. Sikorski, L. Serpell, E. Gazit and G. Archontis, Biophys. J., 2009, 96, 5020-5029.

21 A. Handelman, N. Kuritz, A. Natan and G. Rosenman, Langmuir, 2016, 32, 2847-2862.
22 E. Mayans, G. Ballano, J. Casanovas, A. Diaz, M. M. PerezMadrigal, F. Estrany, J. Puiggali, C. Cativiela and C. Aleman, Chem. - Eur. J., 2015, 21, 16895-16905.

23 T. O. Mason, D. Y. Chirgadze, A. Levin, L. Adler-Abramovich, E. Gazit, T. P. J. Knowles and A. K. Buell, ACS Nano, 2014, 8, 1243-1253.

24 R. Huang, W. Qi, R. Su, J. Zhao and Z. He, Soft Matter, 2011, 7, 6418-6421.

25 R. Huang, Y. Wang, W. Qi, R. Su and Z. He, Nanoscale Res. Lett., 2014, 9, 653.

26 X. Wang, Y. C. Chen and B. Li, RSC Adv., 2015, 5, 8022-8027.

27 R. Wei, C.-C. Jin, J. Quan, H.-l. Nie and L.-M. Zhu, Biopolymers, 2013, 101, 272-278.

28 M. A. Ziganshin, I. G. Efimova, A. A. Bikmukhametova, V. V. Gorbachuk, S. A. Ziganshina, A. P. Chuklanov and A. A. Bukharaev, Prot. Met. Phys. Chem. Surf., 2013, 49, 274-279.

29 V. V. Korolkov, S. Allen, C. J. Roberts and S. J. B. Tendler, Faraday Discuss., 2013, 166, 257-267.

30 M. A. Ziganshin, A. A. Bikmukhametova, A. V. Gerasimov, V. V. Gorbatchuk, S. A. Ziganshina and A. A. Bukharaev, Prot. Met. Phys. Chem. Surf., 2014, 50, 49-54.

31 J. Wang, K. Liu, L. Yan, A. Wang, S. Bai and X. Yan, ACS Nano, 2016, 10, 2138-2143.

32 D. V. Soldatov, I. L. Moudrakovski, E. V. Grachev and J. A. Ripmeester, J. Am. Chem. Soc., 2006, 128, 6737-6744.

33 C. H. Görbitz, Chem. - Eur. J., 2007, 13, 1022-1031.

34 R. Afonso, A. Mendes and L. Gales, J. Mater. Chem., 2012, 22, 1709-1723.

35 R. Anedda, D. V. Soldatov, I. L. Moudrakovski, M. Casu and J. A. Ripmeeste, Chem. Mater., 2008, 20, 2908-2920.

36 S. Guha, T. Chakraborty and A. Banerjee, Green Chem., 2009, 11, 1139-1145.

37 A. Comotti, S. Bracco, G. Distefano and P. Sozzani, Chem. Commun., 2009, 284-286.

38 R. V. Afonso, J. Durao, A. Mendes, A. M. Damas and L. Gales, Angew. Chem., 2010, 122, 3098-3100.

39 A. Comotti, A. Fraccarollo, S. Bracco, M. Beretta, G. Distefano, M. Cossi, L. Marchese, C. Riccardi and P. Sozzani, CrystEngComm, 2013, 15, 1503-1507.

40 S. Guha, M. G. B. Drew and A. Banerjee, CrystEngComm, 2009, 11, 756-762.

41 C. H. Görbitz, Acta Crystallogr., Sect. B: Struct. Sci., 2002, 58, 849-854.

42 T. J. Burchell, D. V. Soldatov and J. A. Ripmeester, J. Struct. Chem., 2008, 49, 188-191.

43 M. A. Ziganshin, I. G. Efimova, V. V. Gorbatchuk, S. A. Ziganshina, A. P. Chuklanov, A. A. Bukharaev and D. V. Soldatov, J. Pept. Sci., 2012, 18, 209-214.

44 C. H. Görbitz, Acta Chem. Scand., 1998, 52, 1343-1349.

45 C. H. Görbitz, Acta Crystallogr., Sect. C: Cryst. Struct. Commun., 1999, 55, 670-672.

46 S. N. Mitra and E. Subramanian, Biopolymers, 1994, 14, 1139-1143.

47 C. H. Gorbitz, Chem. - Eur. J., 2001, 7, 5153-5159.

48 J. D. Halley and D. A. Winkler, Complexity, 2008, 14, 10-17. 
49 W. L. F. Armarego and C. L. L. Chai, Purification of Laboratory Chemicals, Oxford, Butterworth-Heinemann, UK, 2009.

50 L. S. Yakimova, M. A. Ziganshin, V. A. Sidorov, V. V. Kovalev, E. A. Shokova, V. A. Tafeenko and V. V. Gorbatchuk, J. Phys. Chem. B, 2008, 112, 15569-15575.

51 M. A. Ziganshin, A. V. Gerasimov, V. V. Gorbatchuk and A. T. Gubaidullin, J. Therm. Anal. Calorim., 2015, 119, 1811-1816.

52 M. A. Ziganshin, A. V. Gerasimov, S. A. Ziganshina, N. S. Gubina, G. R. Abdullina, A. E. Klimovitskii, V. V. Gorbatchuk and A. A. Bukharaev, J. Therm. Anal. Calorim., 2016, 125, 905-912.

53 I. G. Efimova, M. A. Ziganshin, V. V. Gorbatchuk, D. V. Soldatov, S. A. Ziganshina, A. P. Chuklanov and A. A. Bukharaev, Prot. Met. Phys. Chem. Surf., 2009, 45, 525-528.

54 A. K. Gatiatulin, M. A. Ziganshin, G. F. Yumaeva, A. T. Gubaidullin, K. Suwinska and V. V. Gorbatchuk, RSC Adv., 2016, 6, 61984-61995.

55 M. A. Ziganshin, A. V. Yakimov, G. D. Safina, S. E. Solovieva, I. S. Antipin and V. V. Gorbatchuk, Org. Biomol. Chem., 2007, 5, 1472-1478.

56 R. M. Barrer, J. Inclusion Phenom., 1983, 1, 105-123.
57 D. W. Breck, W. G. Eversole, R. M. Miltont, T. B. Reed and T. L. Thomas, J. Am. Chem. Soc., 1956, 78, 5963-5972.

58 V. V. Gorbatchuk, M. A. Ziganshin, B. N. Solomonov and M. D. Borisover, J. Phys. Org. Chem., 1997, 10, 901-907.

59 A. V. Gerasimov, M. A. Ziganshin, A. E. Vandyukov, V. I. Kovalenko, V. V. Gorbatchuk, A.-M. Caminade and J.-P. Majoral, J. Colloid Interface Sci., 2011, 360, 204-210.

60 V. V. Gorbatchuk, A. K. Gatiatulin, M. A. Ziganshin, A. T. Gubaidullin and L. S. Yakimova, J. Phys. Chem. B, 2013, 117, 14544-14556.

61 Hydrogen Bonding, ed. M. D. Joesten and L. J. Schaad, Marcel Dekker Inc., New York, 1974.

62 X. Yan, Y. Cui, Q. He, K. Wang and J. Li, Chem. Mater., 2008, 20, 1522-1526.

63 H. Geng, L. Ye, A.-Y. Zhang, Z. Shao and Z.-G. Feng, J. Colloid Interface Sci., 2017, 490, 665-676.

64 K. Ariga, J. Kikuchi, M. Naito, E. Koyama and N. Yamada, Langmuir, 2000, 16, 4929-4939.

65 P. Bairi, K. Minami, J. P. Hill, W. Nakanishi, L. K. Shrestha, C. Liu, K. Harano, E. Nakamura and K. Ariga, ACS Nano, 2016, 10, 8796-8802. 